\title{
Advance Directive Completion by Elderly Americans: A Decade of Change
}

\author{
Maria J. Silveira, MD, MA, MPH, ${ }^{* \dagger}$ Wyndy Wiitala, PhD, ${ }^{*}$ and John Piette, PhD ${ }^{* \dagger}$
}

OBJECTIVES: To describe trends in advance directive (AD) completion from 2000 to 2010 and to explore the relationship between $\mathrm{AD}$ and hospitalization and hospital death at the end of life.

DESIGN: Retrospective cohort study.

SETTING: Health and Retirement Study (HRS).

PARTICIPANTS: HRS participants who died between 2000 and 2010 and were aged 60 and older at death $(\mathrm{N}=6,122)$.

MEASUREMENTS: Trends over time in rates of $\mathrm{AD}$ completion, hospitalization before death, and death in hospital are described. The association between trends in $\mathrm{AD}$ completion and hospital death was then assessed by comparing nested, multivariable logistic regression models predicting the odds of hospital death over time with and without adjusting for $\mathrm{AD}$ status and sociodemographic characteristics. The complex sampling design was accounted for in all analyses.

RESULTS: The proportion of decedents with an $\mathrm{AD}$ increased from $47 \%$ in 2000 to $72 \%$ in 2010 . At the same time, the proportion of decedents with at least one hospitalization in the last 2 years of life increased from $52 \%$ to $71 \%$, and the proportion dying in the hospital decreased from $45 \%$ to $35 \%$. After adjusting for confounding by sociodemographic characteristics, the trend in declining hospital death over the decade was negligibly associated with the greater use of ADs.

CONCLUSION: There has been a significant increase in rates of $\mathrm{AD}$ completion over the last decade, but this trend has had little effect upon hospitalization and hospital death, suggesting that $\mathrm{AD}$ completion is unlikely to stem hospitalization before death. J Am Geriatr Soc 62:706$710,2014$.

Key words: advance care planning; end of life; advance directives

From the "Center for Clinical Management Research, Ann Arbor Veterans Affairs Medical Center, and "Division of General Medicine, Department of Internal Medicine, University of Michigan, Ann Arbor, Michigan.

Address correspondence to Dr. Maria J. Silveira, 2800 Plymouth Road, 16-342E, Ann Arbor MI 48109. E-mail: mariajs@umich.edu

DOI: $10.1111 /$ jgs. 12736
A dvance directives (ADs) summarize preferences for life-sustaining treatment and surrogate decision-maker in the event that one loses decisional capacity and requires medical care. There is robust evidence that ADs achieve their original intent to protect autonomy; individuals with $\mathrm{ADs}$ are more likely to receive the care and surrogate decision-maker of their choice ${ }^{1}$ and less likely to die in the hospital. ${ }^{2,3}$ Although ADs were originally designed to protect autonomy, many hoped that they would also help stem healthcare expenditures on unwanted, aggressive care at the end of life. ${ }^{4}$ There is some evidence that ADs save money for Medicare, but this effect is limited to individuals in high-cost regions of the United States who refuse aggressive care. $^{2}$

Still, ADs have gained the attention of governments, insurers, and healthcare providers as a means of reducing expenditures on unwanted, invasive end-of-life care. Among the government-sponsored efforts to encourage AD completion is the Patient Self-Determination Act (PSDA), which Congress passed in 1991 to require all Medicare-certified institutions to inform hospitalized individuals of their right to complete an AD. Many policy analysts have considered the PSDA a failure-arguing that it has done little to improve rates of $\mathrm{AD}$ completion or advance care planning (ACP) conversations. ${ }^{5-7}$ More recently, Congress considered bills to mandate ACP conversations, Medicare attempted to improve physician reimbursement for activities related to $\mathrm{ACP}$, and private insurers have created incentives to practices to develop systems for eliciting and documenting ADs.

Although a Pew Research poll from 2005 showed that only $29 \%$ of the general public completed an AD, morerecent studies suggest that as many as $70 \%$ of elderly adults do so. ${ }^{3}$ Still, no one has demonstrated that these numbers are part of a consistent trend over time, and no one has compared population-based trends in $\mathrm{AD}$ completion with trends in hospitalization and place of death given the results of other individual-level studies showing an association between AD status and likelihood of dying in a hospital. Population-level trend analyses could help policymakers understand the potential effects of policy efforts to promote use of $\mathrm{ADs}$ and set realistic benchmarks for efforts to complete them. 
The current study examined the completion of ADs by a representative population of older Americans from 2000 to 2010. Trends in $\mathrm{AD}$ completion were compared with trends in hospitalization and hospital death over the same period of time to gauge the potential effect that ADs have had on hospital care at the end of life.

\section{METHODS}

\section{Data and Study Sample}

Data from the Health and Retirement Study (HRS), a biennial longitudinal survey of a nationally representative cohort of U.S. adults aged 51 and older, were used. ${ }^{8}$ For more details about HRS sampling, data collection procedures, and measures, see ${ }^{8}$ or http://hrsonline.isr.umich.edu. The analytical sample included individuals who died between 2000 and 2010 and were aged 60 and older at death. Ninety-two percent of these subjects had a proxy who completed an interview after the subject's death that included information about the subject's use of ADs. Ageeligible decedents with proxy surveys were not significantly different in sex or Hispanic status than those without proxy surveys but were less educated (mean 11.3 vs $12.7 \mathrm{yr}$ ) and more likely to be white.

\section{Variables of Interest}

The variables of interest came from proxies' responses to HRS after death surveys (2002-2010) regarding the decedent's circumstances at death, specifically, whether the subject completed a living will (LW) or appointed a surrogate decision-maker in writing (durable power of attorney for health care (DPAHC)). LWs were defined as "written instructions about the treatment or care decedents wanted to receive during the final days of their lives." A DPAHC was defined as "any legal arrangements for a specific person or persons to make decisions about the decedent's care or medical treatment if he or she could not make those decisions him or herself." Decedents were considered to have an $\mathrm{AD}$ if the proxy reported that, at the time of death, the person had a LW, DPAHC, or both. In initial analyses, the characteristics of these decedents were compared with those of decedents who had neither a LW nor a DPAHC. Whether the decedent was hospitalized at least once in the 2 years before death (yes/no), the number of hospitalizations and hospital days in the 2 years before death, and whether the person's death occurred in a hospital (yes/no) were also examined. (Questions used to determine these data are available upon request.)

Variation in $\mathrm{AD}$ and hospital use was examined according to year of death. Analyses controlled for potential confounding according to differences across splined time points in the distribution of patients according to age, sex, race (white, black, other), marital status (married, partnered, other), educational attainment $(<$ high school, high school, $\geq$ some college), and nursing home status (whether the subject had stayed overnight in a skilled nursing facility in the last 2 years) to account for demographic shifts in the population over time. Subjects reported each of these covariates during interviews before death.

\section{Analyses}

Important clinical and sociodemographic characteristics were tabulated to describe the population of subjects and their proxies, and trends over time in potential demographic confounders were examined, stratified according to $\mathrm{AD}$ status. Rates of $\mathrm{AD}$ completion were determined according to year of death, stratified according to type of $\mathrm{AD}$, using the proportion command in STATA version 12.1 (STATA Corp, College Station, TX). Similarly, rates of hospitalization before death and the proportion of decedents who died in the hospital were determined. Trends over time were tested using linear regression.

To measure the magnitude of the effect of $\mathrm{ADs}$ on rates of hospital death over the decade, predicted probabilities were graphed, and coefficients from four nested, multivariable logistic regression models predicting the odds of hospital death (with and without sociodemographic characteristics and $\mathrm{AD}$ status as variables in the model) were compared. The same procedure was followed to estimate the magnitude of the effect of ADs on rates of hospitalization. In these models, time was modeled as a linear spline with three nodes. By modeling time as a spline, any changes in relationships over time could be identified and depicted with smooth curves as opposed to jagged polygons. Three nodes were chosen to obtain the right amount of detail in any figures drafted, without creating too much "noise."

In all analyses, HRS's complex sampling design ${ }^{8}$ was accounted for using the sampling weight from the subject's last interview before death (while community dwelling) as listed in the HRS 2010 Tracker File. All statistical analyses were performed using STATA version 12.1.

\section{Ethical Considerations}

The University of Michigan exempted this study from institutional review board review.

\section{RESULTS}

\section{Study Population}

The sample included data from proxy interviews for 6,122 individuals who died between 2000 and 2010, of whom 6,005 had AD status available. Decedents were on average $81.0 \pm 9.6$ years old at death (range 60-111). There were statistically significant differences between subjects with and without ADs in sex, race, ethnicity, education, marital status, and place of death $(P<.001)$ (Table 1$)$.

According to proxy reports, $67 \%$ of subjects had a week or more between the start of the "final illness" and death. Before death, decedents had heart disease $(54 \%)$, depression $(48 \%)$, cancer $(35 \%)$, cerebrovascular disease $(25 \%)$, lung disease $(25 \%)$, and memory deficits $(48 \%)$. Decedents died in hospitals (38\%), homes $(27 \%)$, and nursing homes $(23 \%)$ more often than anywhere else; few died in hospice facilities (8\%).

\section{Characteristics of Proxy Respondents}

Proxy respondents were adult children $(47 \%)$, spouses $(35 \%)$, and other relatives $(13 \%)$ who were interviewed 
Table 1. Population-Weighted Characteristics of Study Subjects $(\mathrm{N}=6,005)$

\begin{tabular}{|c|c|c|}
\hline Characteristic & $\begin{array}{l}\text { Advance } \\
\text { Directive, } \\
n=3,795\end{array}$ & $\begin{array}{c}\text { No Advance } \\
\text { Directive, } \\
n=2,210\end{array}$ \\
\hline \multicolumn{3}{|l|}{ Sex, \% } \\
\hline Female & 56 & 50 \\
\hline Male & 44 & 51 \\
\hline \multicolumn{3}{|l|}{ Race, \% } \\
\hline White & 90 & 70 \\
\hline Black & 9 & 26 \\
\hline Other & 1 & 4 \\
\hline Hispanic, \% & 4 & 13 \\
\hline \multicolumn{3}{|l|}{ Education, \% } \\
\hline$<$ High school & 33 & 50 \\
\hline High school & 50 & 39 \\
\hline$\geq$ Some college & 11 & 7 \\
\hline Unknown & 6 & 4 \\
\hline \multicolumn{3}{|c|}{ Legal marital status at time of death, $\%$} \\
\hline Married & 37 & 48 \\
\hline Widowed & 51 & 36 \\
\hline $\begin{array}{l}\text { Annulled, divorced, } \\
\text { separated }\end{array}$ & 10 & 11 \\
\hline Never married & 3 & 4 \\
\hline \multicolumn{3}{|l|}{ Place of death, \% } \\
\hline Hospital & 33 & 45 \\
\hline Home & 26 & 30 \\
\hline Nursing home & 27 & 17 \\
\hline Hospice & 10 & 5 \\
\hline Assisted living & 2 & 0 \\
\hline Other & 2 & 3 \\
\hline Lived alone at time of death, \% & 77 & 69 \\
\hline Nursing facility resident, \% & 39 & 24 \\
\hline Year of death, mean (range) & $\begin{array}{l}2005 \\
(2000-2010)\end{array}$ & $\begin{array}{l}2005 \\
(2000-2010)\end{array}$ \\
\hline Age at death, mean (range) & $82.3(60-108)$ & $78.7(60-111)$ \\
\hline $\begin{array}{l}\text { Number of living children, } \\
\text { mean (range) }\end{array}$ & $3(0-22)$ & $4(0-16)$ \\
\hline
\end{tabular}

Counts are not available for population-weighted data. Some totals do not add to $100 \%$ because of rounding. $P<.001$ for all tabulations.

over the telephone $(41 \%)$ or in person $(59 \%)$. Interviews occurred a mean of $13.2 \pm 8.9$ months after the decedent's death (range 0-76 months); 10\% occurred more than 24 months after the decedent's death.

\section{AD Authorship}

$\mathrm{AD}$ data were available for $98 \%$ of the sample. Of those with $\mathrm{AD}$ data, $63 \%$ had some kind of $\mathrm{AD}$ before death; $45 \%$ had a LW, $57 \%$ had a DPAHC, and $38 \%$ had both. There was a statistically significant increase in the proportion of individuals with ADs throughout the decade, from $47 \%$ in 2000 to $72 \%$ in $2010(P<.001)$ (Figure 1).

DPAHCs were more common than LWs for all 10 years. Although the rates of DPAHCs and LWs increased over the decade, DPAHC completion rates increased more rapidly over time (DPAHC: $\beta=0.023,95 \%$ confidence interval $(\mathrm{CI})=0.018-0.028 ; \mathrm{LW}: \beta=0.014$, $95 \% \mathrm{CI}=0.010-0.018$ ).

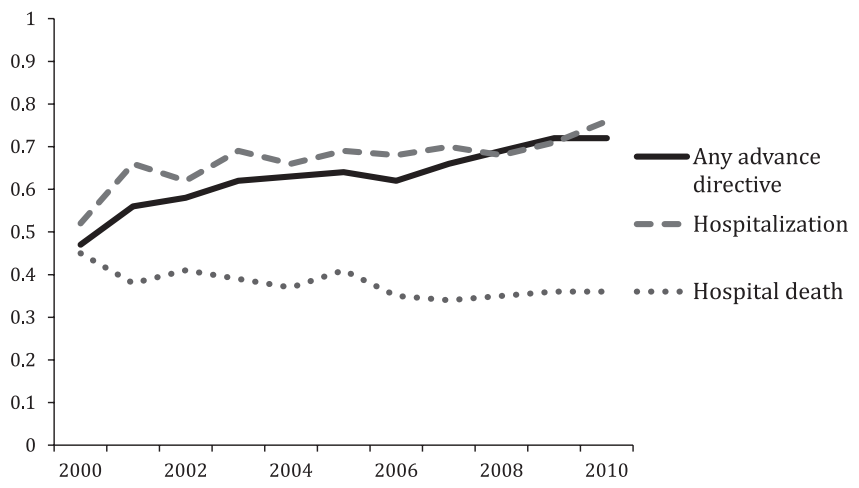

Figure 1. Population-weighted rates of advance directive completion, hospitalization, and hospital death in the United States (2000-2010).

\section{Timing of Authorship}

For decedents for whom dates of AD completion were provided, LWs $(\mathrm{n}=1,440)$ and DPAHCs $(\mathrm{n}=1,836)$ were completed a median of 22 months before death (LW mean $47.6 \pm 63.6$; DPAHC mean $44.5 \pm 58.4$ ). Over the 10 -year period, the time between date of $\mathrm{AD}$ completion and death increased (LWs: $\quad \beta=1.44, \quad 95 \% \quad \mathrm{CI}=-0.33-2.54$, $P=.012 ; \quad$ DPAHCs: $\quad \beta=1.49, \quad 95 \% \quad \mathrm{CI}=0.52-2.45$, $P=.003)$. For example, in 2000, DPAHCs and LWs were completed a mean of 36.9 and 51.7 months before death, respectively. By 2010, DPAHCs and LWs were completed a mean of 40.3 and 54.6 months before death, respectively.

\section{Trends in Hospitalization and Length of Stay}

Over the decade, the odds of hospitalization and the number of hospitalizations before death increased. The unadjusted odds of any overnight hospitalization during the 2 years before death increased from $52 \%$ in 2000 to $71 \%$ in 2010 (odds ratio $(\mathrm{OR})=1.06, P<.001$ per year) (Figure 1 ). Similarly, the number of hospitalizations per decedent increased from a mean of 2.6 in 2000 to 3.4 in 2010 $(\beta=0.77,95 \% \mathrm{CI}=0.04-0.12, P<.001)$.

During the same period, the number of days spent in the hospital and the odds of dying in the hospital decreased. The average number of days in the hospital during the last 2 years of life decreased from a mean of 21.8 in 2000 to 14.3 in 2010 , but this trend was not statistically significant $(\beta=-0.75,95 \% \mathrm{CI}=-2.11-0.61)$. The proportion of subjects dying in the hospital decreased from $45 \%$ in 2000 to $35 \%$ in 2010 (OR $=0.96,95 \%$ $\mathrm{CI}=0.95-0.99, P<.001)($ Figure 1$)$.

\section{Relationship Between ADs, Hospitalization, and Hospital Death}

ADs were positively associated with hospitalization but negatively associated with in-hospital death. Subjects with ADs had higher adjusted odds of hospitalization (adjusted OR $(\mathrm{aOR})=1.45,95 \% \mathrm{CI}=1.29-1.62, P<.001)$ but lower adjusted odds of hospital death $(\mathrm{aOR}=0.80,95 \%$ $\mathrm{CI}=0.72-0.89, P<.001)$.

To determine exactly how much of the decrease in hospital deaths over the decade was due to trends in $\mathrm{AD}$ 
completion as opposed to sociodemographic shifts in the population, nested models predicting hospital death with and without $\mathrm{ADs}$ and sociodemographic characteristics were compared. In models not adjusting for sociodemographic characteristics, ADs had a mild inverse effect on odds of dying in the hospital (Appendix S1, Graphs A and B), especially during the first half of the decade, but after adjusting for sociodemographic characteristics, the effect of ADs on hospital death decreased by half (Appendix S1, Graphs C and D). Table 2 compares coefficients of models with and without $\mathrm{ADs}$ with and without sociodemographic characteristics.

\section{DISCUSSION}

Over the last decade, there has been a $25 \%$ increase in $\mathrm{AD}$ completion rates among older Americans to an all time high of $72 \%$ by 2010 . Increasing use of DPAHCs, which were more popular than LWs for each year between 2000 and 2010, seem to be the primary driver of the increase in rates. In addition to increasing acceptance of $\mathrm{ADs}$ over the decade, these data indicate that people were adopting them earlier over time - as many as 3 months earlier in 2010 than in 2000.

The increased prevalence of ADs observed is consistent with prior research using proxy- and subject-reported data. ${ }^{4,5}$ What is likely to explain these trends? It may be that these changes are the result of the PSDA, which mandates that every institution inform individuals upon admission of their right to complete an AD. Although it is likely that this is contributory, the PSDA has been in effect since 1991, and despite this, the AD completion rate in 2000 was only $47 \%$. It is more likely that demographic changes in the aging population and a shift in society's familiarity with ADs and willingness to complete them explain the trends observed. High-profile stories such as that of Terry Schiavo ${ }^{11}$ and the growing collective experience of the baby boomers has driven this shift. ${ }^{12}$ Over the decade, ADs have penetrated public discourse, to the point where they are dinner conversation at the senior living center, ${ }^{13}$

Table 2. Regression Coefficients for Four Nested Logistic Regression Models Predicting the Odds of Dying in a Hospital

\begin{tabular}{lrrrr}
\hline & \multicolumn{4}{c}{ Model } \\
\cline { 2 - 5 } \multicolumn{1}{r}{ Variable } & A & B & C & D \\
\hline Time point 1 & -0.02 & 0.00 & 0.02 & 0.03 \\
Time point 2 & -0.06 & -0.08 & -0.11 & -0.12 \\
Time point 3 & 0.30 & 0.35 & 0.38 & 0.39 \\
Advance directive & & $-0.49^{\mathrm{a}}$ & & $-0.22^{\mathrm{a}}$ \\
Sociodemographic & & & Included & Included \\
characteristics & & & & \\
\hline
\end{tabular}

Variables included in models: (A) year of death; (B) year of death and advance directive status; (C) year of death and sociodemographic characteristics; and (D) year of death, sociodemographic characteristics, and advance directive status. Time points were selected based on a linear spline of subject's year of death (Time point $1=2000-2003$; Time point $2=2004-2006$; Time point $3=2007-2010$ ).

${ }^{\mathrm{a} P}<.001$. are on the nightly news and are searchable on Wikipedia. Where once many were ignorant of LWs and DPAHCs, now the majority of those polled have an accurate understanding of what they are. ${ }^{10}$

In general, the growing popularity of $\mathrm{ADs}$ is good news. Over the last decade, it has been demonstrated that individuals who complete $\mathrm{ADs}$ are more likely to have their wishes for treatment and surrogate decision-maker respected. ${ }^{1}$ There is proof that ADs fulfill the promise to protect autonomy. Still, many would like ADs to do much more than ensure that people's wishes are respected. The results of the current study should serve as a warning to those who hope that ADs may, in and of themselves, reduce rising rates of hospitalization and expenditures at the end of life.

Studies have demonstrated that individuals with ADs are less likely to die in a hospital, ${ }^{2}$ and some might conclude from these that ADs prevent hospital death, but the findings of the current study suggest that the relationship between $\mathrm{ADs}$ and hospital death may not be causative. In the current study, increasing rates of $\mathrm{AD}$ completion did little to explain decreasing rates of hospital death over the decade; the same is true for rates of hospitalization.

Given prior evidence that the wishes expressed in a LW cannot be extrapolated to predict other preferences, ${ }^{14,15}$ it seems unlikely that that a piece of paper summarizing one's wishes for surrogate decision-maker and life-sustaining treatment would have a large effect on one's likelihood of being hospitalized or dying in the hospital. To stem hospitalization rates, the decisions to hospitalize, die in hospice, or die in the hospital must be addressed more directly. It may be that ACP conversations in which individuals are given the choice not to be hospitalized and provided with the appropriate support to safely and comfortably stay home (e.g., with hospice) are much more likely to affect hospitalization rates than $\mathrm{ADs}$ are; programs incorporating ADs into a comprehensive program of ACP show that to be the case. ${ }^{16,17}$

The authors of the current study believe that these conclusions accurately represent current experience with ADs. The sample size was large and representative of elderly Americans who died between 2000 and 2010, providing sufficient power and allowing the findings to be extrapolated to the U.S. population. Nevertheless, there are limitations that must be considered. Retrospective proxy reports were relied on for the outcomes of interest, and this raises concern regarding the accuracy of the data. Proxies who may also have been the decedents' surrogate may have been psychologically driven to report greater concordance between the person's wishes and the outcomes of decision-making, and because many proxies were surveyed more than 12 months after the subjects' deaths, their responses are subject to recall bias. Geography, a variable that has been shown to affect the strength of the relationship between ADs and hospitalization in high-spending regions, was not accounted for. ${ }^{2,9}$ Last, its focus on the elderly population limits the authors' ability to make any conclusions about younger adults.

In short, these findings suggest that ADs are increasingly popular but alone are insufficient to stem increasing rates of hospitalization or account for increasing rates of hospital death. Although it is important to continue to 
encourage $\mathrm{ADs}$ (to protect autonomy), those looking to reshape end-of-life care should create systems that promote ACP. Future research will need to examine how trends in ACP affect trends in hospitalization and place of death.

\section{ACKNOWLEDGMENTS}

Conflict of Interest: There was no funding for this study.

Author Contributions: Silveira: study concept and design, data management and analysis, preparation of manuscript. Wiitala: analytical design. Piette: study design, analytical design, preparation of manuscript.

Sponsor's Role: No sponsors. The authors alone are responsible for the views, opinions, and conclusions expressed herein.

\section{REFERENCES}

1. Silveira MJ, Kim SY, Langa KM. Advance directives and outcomes of surrogate decision making before death. N Engl J Med 2010;362:1211-1218.

2. Nicholas LH, Langa KM, Iwashyna TJ et al. Regional variation in the association between advance directives and end-of-life Medicare expenditures. JAMA 2011;306:1447-1453.

3. Teno JM, Gruneir A, Schwartz Z et al. Association between advance directives and quality of end-of-life care: A national study. J Am Geriatr Soc 2007;55:189-194.

4. White DB, Arnold RM. The evolution of advance directives. JAMA 2011;306:1485-1486.

5. Emanuel EJ, Weinberg DS, Gonin R et al. How well is the Patient SelfDetermination Act working? An early assessment Am J Med 1993;95: 619-628.

6. Leahman D. Why the Patient Self-Determination Act has failed. N C Med J 2004;65:249-251.

7. Kring D. The Patient Self-Determination Act: Has it reached the end of its life? JONAS Healthc Law Ethics Regul 2007;9:125-131.

8. Juster F, Suzman R. An overview of the Health and Retirement Study. J Hum Resour 1995;30(Suppl):S7-S56.

9. PR Newswire. Legal Zoom.com national survey shows awareness of importance of living wills increasing, but most Americans still unprotected. Los Angeles, CA:PR Newswire, October 18, 2005.
10. More Americans discussing — and planning — end-of-life treatment [on-line]. Available at http://people-press.org/files/legacy-pdf/266.pdf Accessed October $1,2012$.

11. PRNewswire. Schiavo case stimulates interest in living wills. Tallahasee, FL: PRNewswire, March 17, 2005.

12. Stark A. "Susan Sontag, William F. Buckley and Care at the End of Life." Huffpost Healthy Living, May 6, 2013 [on-line]. Available at http://www. huffingtonpost.com/andrew-stark/end-of-life-care_b_3223460.html Accessed January 31, 2014.

13. Schiff R, Rajkumar C, Bulpitt C. Views of elderly people on living wills: Interview study. BMJ 2000;320:1640-1641.

14. Coppola KM, Ditto PH, Danks JH et al. Accuracy of primary care and hospital-based physicians' predictions of elderly outpatients' treatment preferences with and without advance directives. Arch Intern Med 2001;161:431-440.

15. Fischer GS, Tulsky JA, Rose MR et al. Patient knowledge and physician predictions of treatment preferences after discussion of advance directives. J Gen Intern Med 1998;13:447-454.

16. Hickman SE, Hammes BJ, Moss AH et al. Hope for the future: Achieving the original intent of advance directives. Hastings Cent Rep 2005;35:Spec No:S26-S30.

17. Detering KM, Hancock AD, Reade MC et al. The impact of advance care planning on end of life care in elderly patients: Randomised controlled trial. BMJ 2010;340:c1345.

\section{SUPPORTING INFORMATION}

Additional Supporting Information may be found in the online version of this article:

Appendix S1. Graphed predicted probabilities from four nested models predicting hospital death rates, 2000-2010.

Please note: Wiley-Blackwell is not responsible for the content, accuracy, errors, or functionality of any supporting materials supplied by the authors. Any queries (other than missing material) should be directed to the corresponding author for the article. 